\title{
The Knowledge of Response to Intervention (RTI) Model Among Early Elementary Levels Supervisors and Learning Disabilities Supervisors and the Obstacles to Its Applications in Kingdom of Saudi Arabia
}

\author{
Bayan Hamdi Aljohani \\ Master Degree in Special Education - Learning Disabilities
}

\begin{abstract}
This study aims to investigate the Response to Intervention (RTI) knowledge among Early Elementary Levels Supervisors and Learning Disabilities Supervisors in Kingdom of Saudi Arabia and the obstacles to its applications. The target population of this study consists of all learning disabilities supervisors (144) and all early Elementary Levels Supervisors (1064) in the Kingdom of Saudi Arabia according to statistics of the Ministry of Education (Ministry of Education), 1437-1438 H.The current study adopts a comparative analytical descriptive approach. Because it suited the nature of the study. After implementing the exclusion criteria in the survey, the sample group was limited to 240 Early Elementary Levels Supervisors and 91 Learning Disabilities Supervisors. The sample was randomly selected. The researcher also prepared the questionnaire as a tool for this study. The results of the study showed that the degree of knowledge of the response to intervention model among the supervisors of learning disabilities and the supervisors of the Early Elementary Levels was high. There were statistically significant differences at the level of significance $(\alpha=0.05)$ between the mean scores of the knowledge level in the RTI model due to the variable (specialization, scientific qualification). The results showed that there were no statistically significant differences at the level $(\alpha=0.05)$ between the mean scores of the knowledge level of the RTI according to the variable (gender, years of experience,).The study concludes with many recommendations including the importance of providing teachers of learning disabilities and early elementary levels teachers with modern approaches of measurement and diagnosis of students with learning disabilities in the field by their supervisors.
\end{abstract}

Keywords: learning Disabilities, Early Elementary Levels, Response to Intervention, RTI, Early Diagnosis, Supervisors

DOI: $10.7176 / \mathrm{JEP} / 10-26-03$

Publication date:September $30^{\text {th }} 2019$

\section{Introduction}

Effective supervision in anticipating problems by treating the negative effects and benefiting from their positive effects.It also helps teachers to face educational problems and deal with them in a systematic and systematic scientific methods. The percentage of children with learning disabilities is about $51.1 \%$ of the total percentage of children with special needs in the Kingdom, which indicates the extent of the prevalence of the problem of learning disabilities in general (Al-Daheri, 2016, p. 12). The term learning disabilities has appeared at the hands( KIRK) in the early 1960s (Abdullah, 2011)

Saudi Arabia started providing special education services for people with learning disabilities for the first time more than twenty years ago (Ministry of Education, 2018). p.610) To be able to determine the type of intervention and assistance needed by the child, and develop appropriate treatment programs for that condition (El-Abed, 2017)

The Intervention Response Model (Gretchen, 2010, p.11) (RTI) emerged, which, in Hohra, relies on prevention of early intervention rather than waiting until failure occurs. In addition, the use of the IQ model is limited and regulated, which is essentially dependent In addition, it uses a standard-based measure of the curriculum as well as standardized achievement tests to determine progress. The most important features are a general survey aimed at early identification of students at risk or progressing slowly and hard (Hoover, 2010, p. 292).

\section{The Study Problem}

The study attempts to identify "What is the difference in knowledge of the intervention response model among the supervisors of learning difficulties and primary grades and the obstacles of its application in Saudi Arabia"?

The main question is subdivided into the following sub-questions:

1 -What is the degree of knowledge of the RTI model among learning disabilities administrators?

2-What is the degree of knowledge of the RTI response model for primary grade supervisors?

3-Are there any statistically significant differences among the supervisors of learning difficulties and primary grades with knowledge of the intervention response model according to variables (specialization, sex, years of 
experience, educational qualification,)?

Objectives of the study:

The objectives of this study are:

.1-Determine the degree of knowledge of the RTI model among the learning difficulties supervisors and the supervisors of the first grades.

.2-Identify the differences of statistical significance among the supervisors of learning difficulties and primary grades by knowledge of the intervention response model (RTI) according to the variables (specialization, gender, years of experience, educational qualification, region.

.3-Identify the obstacles to applying the RTI response model.

the importance of studying:

The present study derives its importance from the following:

\section{-Theoretical significance}

.1-Lack of researches and studies that dealt with the RTI model in light of the loud voices calling for the development of teaching methods related to people with learning difficulties in educational institutions.

.2-The research subject is consistent with the trends, strategies and modern methods globally, which pointed to the importance of the RTI response model in dealing with people with learning disabilities.

\section{-Applied importance}

1-It is hoped that the results of the study will benefit decision-makers in the Ministry of Education to find out the reality of the differences among the supervisors of learning difficulties and primary grades with knowledge of the RTI.

2-It is hoped that the results of this study will place before the educational leadership in the ministry, and those who are responsible for learning difficulties programs, the importance of being supervised primarily in the field of special education and specifically learning difficulties.

3-The study can help to improve the level of the educational system in all its components, in particular the outputs of the achievement of students with learning difficulties through the RTI with new contents that contribute to the early detection of the difficulties they face in learning.

The limits of the study:

The study is limited to the following limits:

1. Objective Limit: Objective limits are to identify the differences between the supervisors of learning difficulties and primary grades by knowledge of the response response model and the obstacles to its application.

2. Human Frontiers: The Human Frontiers are the supervisors of learning difficulties and primary school supervisors at the primary level in the educational departments and supervision offices of the Ministry of Education in Saudi Arabia.

3. Time Limits: The study was applied in the second semester of the academic year 2019.

Spatial boundaries: The study was applied in all regions of Saudi Arabia.Terminology of study

\section{Supervisors of learning disabilities:}

" Is a distinguished teacher specializing in one of the areas of special education - depending on the nature of the program - and the availability of technical and administrative competence, and is responsible for overseeing the educational process and education in all aspects of the program (regulations, $1422 \mathrm{e}$ ).

learning difficulties:

Defined by (Ministry of Education, 2018): "Disorders in one or more basic psychological processes involving understanding and use of written or spoken language that appear in disorders of listening, thinking, speaking, reading, writing (spelling, expression, and calligraphy) and mathematics that are not due to causes Relating to mental, auditory, visual or other disabilities, learning conditions or family care" .

\section{RTI Intervention Response Model:}

(Grosch \& Volpe, 2013, p.258) defined it as: "A model designed for students with different behavioral and educational needs, where the intervention begins by providing intensive instruction to all learners, and following up the progress of all learners to observe the need for a more intensive intervention. Consistent with the student level".

\section{Theoretical framework:}

\section{Intervention Response Model Concept:}

The intervention response model represents a new approach in identifying people with learning disabilities.It is based primarily on the student's ability to respond to evidence-based educational interventions before deciding on the student's eligibility and need for special educational programs (Masoud, 2014). Wixson \& Valencia (2011) shows that the intervention response model is an effective alternative to the traditional model used to identify people with learning disabilities. This model helps teachers to intervene when students have problems with learning, rather than waiting until they fail to refer them to special education services. Benson \& Newman (2010), (Bayat et all, 2010; \& Thomas \& Dykes, 2011) 
Stages of diagnosis using the intervention response model:

(Al-Hamd, 2010; Lannuzzi, 2015; and Pamela et al, 2008) indicated that the identification and diagnostic stages of the response model based on qualitative analysis go through three phases: the first stage: providing activities, methods and teaching methods for reading and others. Stage 3: It is called the specialized educational treatment stage, targeting students who did not respond to the educational interventions in the previous stages.

Objectives of the intervention response model:

Sheldon (2005) and Hoover (2005) argue that the intervention response model through its phases and follow-up frameworks aims to:

1. Promote learning and eliminate failure by providing effective intervention and guidance to as many students as possible.

2. Dealing with the problems and difficulties facing students, which can help address learning difficulties.

3. Accelerate learning for students who need more help and who lack effective learning methods.

4. Address the difficulties students face by providing individual behavioral and educational needs through special education

Disadvantages and criticisms of the intervention response model:

Pamela et al. (2008) argue that there are many critics who argue that the student's lack of response to the intervention response model is disproportionate to the recognition of learning disabilities,

The role of the intervention response model in the development of academic subjectS:

The RTI changes the way teachers decide what should be delivered alongside them to students. Teachers receive valuable information from student data about each student (Simon \& Goes, 2013).

As a result of the criticism of the divergence, it was necessary to find more effective methods and methods to be used in the process of identifying students with learning difficulties (NJCLD, 2005).

Study Methodology and Procedures:

Study Approach:

The descriptive analytical method was used because of its relevance to the nature of the study.

Study population:

The study population consists of all supervisors and supervisors of learning disabilities (144), and all supervisors and supervisors of primary grades (1064), for the academic year (2018-2019).

The study sample:

The sample of the study is limited to (240) supervisors of primary grades, and (91) supervisors of learning difficulties belonging to the educational departments and supervising offices of the Ministry of Education in the Kingdom of Saudi Arabia..

Study Tool:

In the light of the objectives and questions of this study, the researcher in this study used a tool to collect data from the target sample, in order to reach the results. In order to obtain the answers of the respondents to the research questions, the following is a detailed explanation of the study tool:

The questionnaire contains two sections:

Section I includes the personal data of the sample in terms of the following variables:

-Specialization. - Qualification.

-Years of Experience. - Sex.

-Region.

Section II: It includes the themes of the study, namely:

.( Axis I: Knowledge of the RTI response model )18 words

-The second axis: Obstacles to the application of the RTI model by (12) words

Validity of the study tool:

The researcher has verified the validity of the study tool through:

Honest Arbitrators:

The method of virtual honesty was used to ensure the validity and suitability of the tool for research purposes by presenting it to a group of academic arbitrators specialized in the field of special education. The educational supervisors specialized in the Ministry of Education (8) arbitrators were answered by (96\%) that the tool is suitable for the purpose of study.

Stability of the study tool:

Half Fragmentation Split Method:

The correlation coefficient was calculated between the sum of the scores of the individual paragraphs and the sum of the scores of the even paragraphs for each dimension. The stability of the questionnaire, its axes and the total score were calculated using the Cronbach Alfa, where the overall score was( 0.86). This ratio is acceptable for the level of stability of the instrument

Search results and discussion:

This section examines the results of the study, which aimed to learn about the RTI model among the supervisors 
of learning difficulties and primary grades and the obstacles of its application in Saudi Arabia. In addition to identifying the degree of difference between the averages of the responses of the supervisors of the study tool (gender, years of experience, educational qualification, region), the final form of the tool consisted of (30) paragraphs divided into two areas: Second: Obstacles to the Application of the Intervention Response Model (12). The results of the study will be reviewed according to the sequence of their questions as follows:

Question 1: What is the degree of knowledge of the RTI model among learning disabilities administrators? To answer this question, it was revealed that there are differences in the values of the tool fields due to the differences in the general information of the study sample members.

Table (1) shows the arithmetic averages and standard deviations of the knowledge of the RTI model among learning disabilities administrators

\begin{tabular}{|c|c|c|c|}
\hline ترتيب الفقرات تنازلي حسب الوــط الحسابي & standard deviations & $\begin{array}{c}\text { arithmetic } \\
\text { averages }\end{array}$ & الرقم \\
\hline 1 & 0.71 & 4.35 & 1 \\
\hline 14 & 0.77 & 4.01 & 2 \\
\hline 18 & 1.16 & 3.67 & 3 \\
\hline 3 & 0.79 & 4.24 & 4 \\
\hline 9 & 0.84 & 4.07 & 5 \\
\hline 11 & 0.79 & 4.04 & 6 \\
\hline 17 & 0.79 & 3.96 & 7 \\
\hline 12 & 0.74 & 4.04 & 8 \\
\hline 16 & 0.90 & 3.97 & 9 \\
\hline 5 & 0.79 & 4.15 & 10 \\
\hline 15 & 0.78 & 4.01 & 11 \\
\hline 10 & 0.82 & 4.05 & 12 \\
\hline 6 & 0.71 & 4.14 & 13 \\
\hline 8 & 0.74 & 4.12 & 14 \\
\hline 7 & 0.85 & 4.13 & 15 \\
\hline 4 & 0.76 & 4.23 & 16 \\
\hline 2 & 0.68 & 4.27 & 17 \\
\hline \multirow[t]{2}{*}{13} & 0.87 & 4.03 & 18 \\
\hline & 0.81 & 4.08 & المجموع \\
\hline
\end{tabular}

Table (1) shows that the averages ranged between (4.35-3.67), where paragraph (1) and its text (the intervention response model is suitable for all pupils for early intervention) ranked first with an average of (4.35). Paragraph (3) and its text (there is a similarity between the intervention response model and the intervention procedures before the assignment, which eliminates the use of the intervention response model) in the last rank with an average of (3.67). - 1.6 (weak), 1.7 - 3.3 (medium) and 3.4 - 5 (high).

This study is consistent with the Martinez \& Young (2011) and Pavoni et al (2012) Fuchs \& Vaughn (2012) Preferred (2014): Abu Hussein and Samary (2016): A Good Study (2016). It indicates the advanced scientific and cognitive level of learning difficulties supervisors and their academic qualification level, and their great role in providing early intervention services opportunities to detect cases of people with learning difficulties early. Respond to intervention in the diagnosis of people with learning disabilities. 
Question 2: What is the degree of knowledge of the RTI model for primary grade administrators?

Table (8) shows the arithmetic averages and standard deviations of the degree of knowledge of the RTI response model for primary graders

\begin{tabular}{|c|c|c|c|}
\hline |ترتيب الفقرات تنازلي حسب الوـط الحسابي & | الانحراف المعياري & الو_ط الحسابي | & الرقم \\
\hline 2 & 0.97 & 3.73 & 1 \\
\hline 6 & 0.94 & 3.59 & 2 \\
\hline 17 & 0.89 & 3.23 & 3 \\
\hline 7 & 1.01 & 3.53 & 4 \\
\hline 13 & 1.23 & 3.37 & 5 \\
\hline 11 & 1.11 & 3.41 & 6 \\
\hline 12 & 1.23 & 3.40 & 7 \\
\hline 15 & 0.99 & 3.33 & 8 \\
\hline 18 & 1.24 & 3.22 & 9 \\
\hline 10 & 1.02 & 3.42 & 10 \\
\hline 14 & 1.11 & 3.35 & 11 \\
\hline 16 & 1.08 & 3.29 & 12 \\
\hline 8 & 1.01 & 3.48 & 13 \\
\hline 9 & 0.96 & 3.42 & 14 \\
\hline 1 & 1.11 & 3.74 & 15 \\
\hline 5 & 1.16 & 3.63 & 16 \\
\hline 3 & 1.21 & 3.69 & 17 \\
\hline \multirow[t]{2}{*}{4} & 1.06 & 3.67 & 18 \\
\hline & 1.07 & 3.47 & لمجموع \\
\hline
\end{tabular}

Table (8) shows that the averages ranged between (4.74 - 3.22), where paragraph (15) and read (the availability of school administration support is very important for the application of the intervention response model) ranked first with an average of (4.74). While paragraph (9) and its text (distinguish the intervention response model between students with learning disabilities and late students) ranked last with an average of (3.22) and the average of use as a whole (3.47), which is a high degree where the researcher adopted a score from 0 to 1.6) (Weak) and 1.7 - 3.3 (medium) and 3.4 - 5 (high).

This study is consistent with the Martinez \& Young (2011) and Pavoni et al (2012) Fuchs \& Vaughn (2012) Preferred (2014): Abu Hussein and Samary (2016): A good study (2016). The supervisors of the primary grades have sufficient general knowledge of the intervention response model. They are because they were more detailed and precise phrases for the response model's procedures To enter.

Question 3: Are there any statistically significant differences among the supervisors of learning disabilities and primary grades with knowledge of RTI according to variables (specialization, gender, years of experience, educational qualification, region)?

Arithmetic averages and standard deviations for the knowledge of the intervention response model (RTI) were calculated according to the specialization variable (Difficulties supervisors and primary grades supervisors).

Table (9) Arithmetic averages, standard deviations and t-test for two independent samples of knowledge of the RTI according to the variable of specialization (learning difficulties supervisors and supervisors of primary grades)

\begin{tabular}{|c|c|c|c|c|c|c|}
\hline مستوى الدلالة & قيمة ت & الانحراف المعياري & |الوط ط الحسابي & العدد & التخصص & \\
\hline .000 & 7.162 & $\begin{array}{l}.426 \\
.772\end{array}$ & $\begin{array}{l}4.08 \\
3.47\end{array}$ & $\frac{91}{240}$ & [ ـشرفي الصفوف صعات الأولية & المعرفة بنموذج الاستجابة \\
\hline
\end{tabular}

The results of the previous table showed that there are statistically significant differences at the level of significance $(\alpha=0.05)$ between the arithmetic averages of the degree of knowledge of the intervention response model (RTI) attributed to the variable of specialization (learning difficulties supervisors, and supervisors of primary grades) where the level of statistical significance.

The results of this study have been agreed with Ateen Study (2019): Al-Shaddadi Study (2009) .The degree of this difference can be explained by the specialized academic qualification of learning disabilities supervisors and their practical field experience in dealing with teachers who apply programs and implement them on students with difficulties. The result also indicates that the members of the learning difficulties supervisors agree to develop methods of detecting people with learning difficulties through their knowledge of the latest methods such as the intervention response model to achieve the maximum benefit for people with learning disabilities.

Arithmetic averages and standard deviations were defined for the knowledge of the RTI according to the gender variable and t-test for two independent samples was used to find the differences. 
Table (10) shows arithmetic averages, standard deviations and t-test for two independent samples of knowledge of RTI according to gender variable

\begin{tabular}{|c|c|c|c|c|c|c|}
\hline مستوى الدلالة & قيمة ت & الانحر اف المعياري & الحسابي & العدد & الجنس & \\
\hline \multirow{2}{*}{.078} & \multirow{2}{*}{-1.768} & .727 & 3.55 & 148 & ذكر & \multirow{2}{*}{ لمعرفة بنموذج الاستجابة } \\
\hline & & .756 & 3.70 & 183 & انثى & \\
\hline
\end{tabular}

The results of the previous table showed that there were no statistically significant differences at the level of significance $(\alpha=0.05)$ between the arithmetic averages of the degree of knowledge of the intervention response model (RTI) according to the gender variable where the level of statistical significance reached(,078).

This result is consistent with the study of Subaie and Omar (2016): This may be due to the fact that the academic programs studied by supervisors are one of both sexes and also because of the multiplicity of means and sources of modern knowledge in our current age, which makes modern information regarding methods of early detection of people with learning disabilities and others reach both sexes.

\section{References}

- Abu Hussein, Widad, and Samari, Munira (2016). Level of knowledge and orientation towards using the intervention response model among teachers of learning disabilities in Riyadh city. Journal of Special Education and Rehabilitation: Foundation of Special Education and Rehabilitation, vol. 4, No. 13, 212-253.

- Abu Shaira, Ahmed (1429 e). Learning difficulties and theory of response to treatment. Al-Jazeera Newspaper, issue 129916.

- Abu Nayan, Ibrahim bin Saad (2015). Educational supervisors 'awareness of parents' participation in learning disabilities programs. International Educational Journal, vol. 4, p. 6, pp. 121--144.

- Management of learning difficulties $(1438 \mathrm{H})$. Guide for learning difficulties programs - Boys in regions and governorates for the academic year $1437 \mathrm{AH} / 143 \mathrm{AH}$. Riyadh: General Directorate of Special Education.

- Al-Battal, Zaid Bin Mohammed, Al-Qahtani, Duha Bint Saif (2017). Obstacles of educational supervision of learning disabilities programs as perceived by supervisors and supervisors in Saudi Arabia. Journal of Special Education and Rehabilitation: Foundation of Special Education and Rehabilitation, vol. 5, No. 19, 47-89.

-alhamed, Khaled (2010). Response to the intervention concept, its components, and methods. Arab Journal of Special Education. M 1, p. 17, pp. 13--39.

- Al-Dahri, Saleh Hassan (2016). Psychology of Learning Disabilities: Foundations and Theories. Amman: The Scientific Hurricane House.

- Zayat, Fathi Mustafa. (2006). The predictive value of identifying and diagnosing learning difficulties between quantitative and qualitative analysis models. International Conference on Learning Disabilities, Riyadh, Saudi Arabia

Al-Zayyat, Fathi Mustafa (2008). Contemporary Issues in Learning Disabilities: Cognitive Psychology Series and Learning Disabilities. Cairo: University Publishing House.

- Subaie, Nahla, Omar, Ghada (2016). The level of organizational commitment among the supervisors of special education and its obstacles and mechanisms to strengthen it in light of some variables. Journal of Special Education and Rehabilitation: Foundation of Special Education and Rehabilitation, Vol. 3, No. 10: 124-160.

- alsalaemeh, Areej Bint Ali (2014). Proposed training program to develop the concept of response to the intervention of employees in the learning disabilities program. Kuwait: Dar Al Messila Publishing \& Distribution.

- Mr. Abdel Hamid Suleiman (2007). The effectiveness of an intensive training program in developing the awareness of educational supervisors of some skills of diagnosing pupils with learning difficulties at the primary stage and treating some reading difficulties in Khamis Mushait province, Saudi Arabia: an experimental study. Educational and Social Studies: Helwan University, Faculty of Education, Vol 13, Vol 3: 117-160.

- Al-Shadadi, Mohammed Bin Tleihan (2009). The role of the educational supervisor in improving the educational performance of teachers with learning difficulties in the region of Medina from the perspective of teachers themselves. Journal of Education: Al-Azhar University - Faculty of Education, p 183, c 3, 523 854.

- The Slave, Bahaa Ahmed (2017). Vision 2030 and the future of Saudi Arabia. Saudi Arabia: Janadriyah Publishing and Distribution.

- Assaf, Saleh (2012). Introduction to behavioral science research. 2nd Floor, Riyadh: Dar Al Zahraa.

Al-Aqeel, Arwa Bint Saleh, Al-Daghmi, Ohood Bint Abdul Rahman (2016). Awareness of the preparedness of workers in the educational difficulties programs of the strategy to respond to the intervention in Al-Jouf region. Journal of Education: Al-Azhar University - Faculty of Education, No. 169, c 2, 670699.

- Alkatiri, Noura bint Ali (2017). Obstacles of educational supervision of learning difficulties programs attached 
to primary schools and ways of development in Riyadh in the light of some variables. Journal of Scientific Research in Education: Ain Shams University - Girls' College of Arts, Sciences and Education p. 18, c 8: 179 - 202.

- almehrig, Khalid bin Mohammed (2017). The training needs of supervisors and supervisors of learning disabilities in Saudi Arabia from the point of view of the study members. Journal of Special Education and Rehabilitation: Foundation of Special Education and Rehabilitation, vol. 5, No. 17, 40-73.

- Thebes, Nadia Jamil (2016). The effectiveness of an early intervention program based on the intervention response theory that supports reading skills and associated sub-skills. Journal of Special Education and Rehabilitation, 4 (14) pp. 39--80.

- Abdullah, Adel (2011). Introduction to Special Education. Cairo: Dar Al Rashad.

-Ateen, Aisha Abdul Rahman Ali (2019). The role of supervisors of learning disabilities in the development of learning disabilities programs in Saudi Arabia. Journal of Special Education-Center for Educational, Psychological and Environmental Information, M4, No. 15, pp. 239-296.

- Kirk Samuel, Gallagher, James, Coleman, Mary, Anna Stowe, Nick (2013). Education for children with special needs. Translated by Amani Mahmoud, 1st Floor, Amman: Dar Al Fikr for Publishing and Distribution.

- Massoud, Khaled Ashour. (2014). The concept of academic self-motivation and achievement as a validator of the diagnostic list of learning difficulties in light of the intervention response model of a sample of primary school students in Misurata, Libya. World of Education. Arab Foundation for Scientific Consultations and Human Resources Development. Libya.

- Favorite, Mustafa (2014). The effectiveness of the intervention response model in the treatment of learning difficulties in primary school students. Journal of Educational Sciences: South Valley University - Faculty of Education in Qena, p 14

- Hallhan, Daniel, Kaufman, James, John, Weiss, Margaret, Martinez, Elizabeth (2007). Learning difficulties: concept, nature, therapeutic education. Translation by Adel Mohammed, Amman: Dar Al Fikr for Publishing and Distribution.

- Ministry of Education (1438H). Annual statistical programs and special education institutes. Saudi Arabia, Riyadh, Teachers Affairs, Special Education Department.

Bayat, M., Mindes, G. \& Covitt, S. (2010). What does RTI (Response to- Intervention) look like in preschool? Early Childhood Education, J. (37), 493-500

-Benson, N \& Newman, J. (2010). Potential utility of actuarial methods for identifying specific learning disabilities. Psychology in the Schools, 47 (6), 539-550

Berkeley, S., Bender, W. N., Peaster, L. G., \& Saunders, L. (2009).- Implementation of response to intervention. A snapshot of Progress. Journal of Learning Disabilities, 42, 85-89.

-Bradley, R.; Danielson, L \& Hallahan, D.(2002). Identification of learning disabilities to practice. Mahwah, NJ: Lawrence Erlbaum Associates

-Drame, E., \& Xu, Y. (2008). Examining sociocultural factors in response to intervention models. Childhood Education, 85(1), 26-32.

Fuchs, L. \& Fuchs, D. (2009). On the importance of a unified model of- responsiveness to intervention. Child Development Perspectives, 3 (1), 41-43.

-Fuchs, Lynn \& Vaughn, Sharon (2012). Responsiveness-to-intervention: A decade later. Journal of learning disabilities, 45(3), 195-203.

-Gretchen, Owocki, (2010). The RTI daily planning book, K-6: Tools and strategies for collecting and assessing reading data \& targeted follow-up instruction. Portsmouth, NH: Heinemann.

-Grosche, Michael \& Volpe, Robert (2013). Response-to-intervention (RTI) as a model to facilitate inclusion for students with learning and behaviour problems. European Journal of Special Needs Education, 28(3), 254269.

-Hoover, J. (2010). Special education eligibility decision making in response to intervention models. Theory into Practice, 49, 289-296

-Ikeda, M. (2012). Policy and practice considerations for Response to Intervention: Reflections and commentary. Journal of Learning Disabilities, 45(3), 274-277.

-Keller-Margulis, M. (2012). Fidelity of implementation framework: A critical need for response to intervention models. Psychology in the Schools, 49(4), 342-352.doi.

-Kuo, N. (2014). Why is response to intervention (RTI) so important that we should incorporate it into teacher education programs and how can online learning help. Journal of Online Learning and Teaching, 10(4), pp.610-624.

Lannuzzi, S. (2015). Response to Intervention. University of Rowan. New Jersey. USA.

-Martinez, Rachel, \& Young, Andria (2011). Response to Intervention: How Is It Practiced and Perceived? International Journal of Special Education, 26(1), pp.44-52. 
-O’Donnell, P. S., \& Miller, D. N. (2011). Identifying students with specific learning disabilities: School psychologists' acceptability of the discrepancy model versus response to intervention. Journal of Disability Policy Studies, 22, 83-94.

-Pamela, M., Douglas, F., \& Lynn, S. (2008). Progress Mnitorig as Essential Practice Within Response to Intervention. Alura Special Education Quarterly.

-Pavoni, Daniel, Ansari, Benita, Rozsi, Michelle, Stephens, Brian, Lange, Trina (2012). Response to Intervention: A Survey of Attitudes and Perceptions. California state university, San Bernardino, retrieved from http://emurillo.org/Classes/Class2/documents/ResponsetoIntervention.doc

-Sheldon, H. (2005). Research Roundup: Response to Intervention- A Primer, Director of Professional Service, NCLD. www.NCLD.org.

-Simon, M., \& Goes, J. (2013). Dissertation and scholarly research: Recipes for success. Seattle, WA: Dissertation Success LLC.

-Sonya, H. (2014). Reading intervention: The effective of leveled literacy intervention. Doctor dissertation, Walden University. UMI Number: 3611522

-Tennessee Department of Education (2013). TNCore RTI2 framework 2013: Implementation Guide. Nashville, TN: Education, Tennessee Department of. Retrieved August 5, 2013, from http://www.tn.gov/education

-Thompson, S. (2010). Response to instruction, English language learners and disproportionate representation: The role of assessment Psicothema, 22 (4), 970-974."

-The National Joint Committee on Learning Disabilities (NJCLD). (2005.) Responsiveness to Intervention and Learning Disabilities. Learning Disability Quarterly, 28(4), 249-260. https://doi.org/10.2307/4126964

-Thomas, S. \& Dykes, F. (2011). Promoting successful transitions: What can we learn from RTI to enhance outcomes for all students? Preventing School Failure, 55 (1), 1-9.

-Werts, Margaret Gessler, Carpenter, Ellen Stahl, Fewell, Caitlin (2014). Barriers and Benefits to Response to Intervention: Perceptions of Special Education Teachers. Rural Special Education Quarterly, 33(2) p3-11.

- Wixson, K. \& Valencia, S. (2011). Assessment in RTI: What teachers and specialists need to know. The Reading Teacher, (64), 466-46. 